\title{
Laboreal
}

Volume $16 \mathrm{~N}^{\circ} 1 \mid 2020$

Quando o trabalho real é tabu

\section{Amianto: uma contaminação sem fronteiras, sem fim e com total impunidade*}

Amianto: una contaminación sin fronteras, sin fin y con total impunidad

Amiante: une contamination sans frontières, sans fin, en toute impunité

Asbestos: contamination without borders, without end and with total impunity

\section{Annie Thébaud-Mony}

Tradutor. Teresa Lello e Christiano Lello

\section{(2) OpenEdition}

\section{Journals}

\section{Edição electrónica}

URL: http://journals.openedition.org/laboreal/16191

DOI: 10.4000/laboreal. 16191

ISSN: 1646-5237

\section{Editora}

Universidade do Porto

\section{Refêrencia eletrónica}

Annie Thébaud-Mony, « Amianto: uma contaminação sem fronteiras, sem fim e com total

impunidade* ", Laboreal [Online], Volume $16 \mathrm{~N}^{0} 1$ | 2020, posto online no dia 01 julho 2020, consultado o 15 setembro 2020. URL : http://journals.openedition.org/laboreal/16191

Este documento foi criado de forma automática no dia 15 setembro 2020.

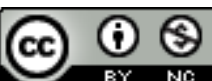

Laboreal está licenciado com uma Licença Creative Commons - Atribuição-NãoComercial 4.0 Internacional. 


\section{Amianto: uma contaminação sem fronteiras, sem fim e com total impunidade*}

Amianto: una contaminación sin fronteras, sin fin y con total impunidad Amiante: une contamination sans frontières, sans fin, en toute impunité Asbestos: contamination without borders, without end and with total impunity Annie Thébaud-Mony

Tradução : Teresa Lello e Christiano Lello

\section{NOTA DO EDITOR}

*Texto originalmente publicado como "Think piece" pela OIT (https://www.ilo.org/ global/topics/safety-and-health-at-work/events-training/events-meetings/world-dayfor-safety/33thinkpieces/WCMS_681629/lang--fr/index.htm).

Tradução [1]: Teresa Lello e Christiano Lello - tlello12@gmail.com

1 Os factos são conhecidos desde finais do séc. XIX: independentemente da variedade (anfíbola ou crisotila), o amianto é prejudicial à saúde e mata. Mas não imediatamente! À exceção dos sinais de fibrose pulmonar, chamada 'asbestose', que podem surgir bastante precocemente quando há uma forte exposição a esta fibra mineral, os sintomas clínicos dos cancros relacionados com o amianto aparecem mais tarde, mesmo algumas décadas depois da contaminação.

2 Apesar de os industriais saberem disso desde a década de 1930, foi preciso esperar pelos trabalhos de Irving Selikoff e da sua equipa (Faculdade de Medicina Monte Sinai da Universidade de Nova Iorque), no início dos anos 1960, para que a dimensão da epidemia de doenças relacionadas com o amianto fosse publicamente considerada uma realidade. As condições de trabalho nas fábricas de amianto no início dos anos 1970 eram 
catastróficas, como nos relata Josette Roudaire, uma antiga operária da fábrica têxtil da AMISOL em Clermont-Ferrand, França (Roudaire, 2018).

3 Foi também nessa altura, meados da década de 1960, que o Brasil, um país que, até aí, muito pouco usava amianto, começou a explorar a maior mina da América Latina: Canabrava - Minaçu, no Estado de Goiás. E, durante as décadas seguintes, é esta mina que vai transformar o Brasil no $3^{\circ}$ produtor mundial, em benefício de duas empresas multinacionais europeias: a Eternit (Suíça) e a Saint Gobain (França).

4 Em termos mundiais, dos $\mathbf{1 8 2}$ milhões de toneladas de amianto produzidos entre 1900 e $2004,80 \%$ foram-no depois de 1960 , ou seja, quando já se conheciam os seus efeitos nocivos à saúde e letais (McCulloch \& Tweedale, 2008).

5 Atualmente, graças aos esforços de uma frente comum de cidadãos, sindicatos e associações, presente em todos continentes, 55 países proibiram o amianto. Mas a extração e o consumo continuam atingindo valores da ordem dos 2,03 milhões de toneladas por ano, segundo os mais recentes números. E, em fevereiro de 2020, a Eternit-Brasil, que explorava a mina de Canabrava - Minaçu, e que encerrara a empresa em 2019, anunciou que retomava "provisoriamente" a sua atividade [2], mas exclusivamente para exportar o remanescente para países asiáticos [3].

6 A dimensão da epidemia de doenças relacionadas com o amianto é conhecida, embora bastante subavaliada, devido à inexequibilidade de diagnósticos e à baixa fiabilidade das fontes estatísticas, em muitos países.

7 As mais recentes estimativas (de mortalidade) dão conta de 255 mil mortes causadas pelo amianto em todo o mundo, das quais 233 mil devido a exposição profissional (Furuya \& al, 2018). Os casos episódicos não são recenseados e as vítimas raramente indemnizadas.

8 No caso do amianto, há três grandes desafios de saúde pública e de justiça que estão na agenda nacional e internacional. O primeiro de todos é a necessidade de travar a epidemia e impedir o aparecimento de novos casos. Trata-se, portanto, de conseguir uma proibição mundial e definitiva do amianto. Foi isso que a OIT vivamente recomendou na sua assembleia geral, em 2006 [ $\left.{ }^{4}\right]$.

9 Uma das vias que poderia apoiar tal objetivo é a Convenção de Roterdão relativa ao Procedimento de Prévia Informação e Consentimento (procedimento PIC: prior informed consent) para determinados produtos químicos e pesticidas perigosos no comércio internacional, e que está em vigor desde 2004 [5].

10 No entanto, tendo em conta as enormes quantidades de amianto espalhadas por edifícios públicos e privados, os sistemas de abastecimento de água e as inúmeras instalações industriais e comerciais, a proibição do amianto não vai resolver tudo. Devem tomar-se medidas para que a eliminação do amianto existente, bem como dos resíduos, seja feita em condições que garantam a proteção dos trabalhadores e dos residentes, evitando-se toda e qualquer nova contaminação pelas poeiras dos trabalhos de remoção e deficiente armazenamento dos resíduos.

11 O segundo desafio é o da justiça para os trabalhadores atingidos e respetivas famílias. No "projeto para a elaboração de programas nacionais para a eliminação das doenças relacionadas com o amianto" [ $\left.{ }^{6}\right]$, a OIT e a OMS recomendam a criação "de um registo central de todos os trabalhadores expostos ao amianto, inclusive no passado". Ainda segundo a OIT e a OMS, "deveria criar-se uma vigilância médica para detetar precocemente todos os sintomas e patologias resultantes da exposição ao amianto". Se 
isso tivesse sido feito há trinta anos, o recenseamento efetivo e oficial das vítimas terlhes-ia permitido o direito de reconhecimento e o direito à indemnização em caso de doença profissional, complementado por outras formas de ressarcimento (falta indesculpável do empregador, Fundo de indemnização das vítimas de amianto). 0 acompanhamento médico deveria ser alargado aos casos de exposição familiar e ambiental, devendo as vítimas em causa beneficiar dos mesmos direitos em termos de indemnização.

12 Finalmente, o último desafio, mas não menos importante, é o do reconhecimento da responsabilidade penal dos empresários industriais nesta catástrofe sanitária mundial. Com efeito, a 3 de março de 2002, o Conselho de Estado (o Supremo Tribunal Administrativo francês) reconheceu a responsabilidade do Estado por "falha (ou omissão) culposa", por não ter adotado e aplicado medidas de prevenção dos riscos relacionados com a exposição dos trabalhadores às poeiras de amianto.

Todavia, apesar da acumulação de provas das estratégias ativas e deliberadas de dissimulação dos efeitos do amianto na saúde, levados a cabo durante anos pelos dirigentes das empresas multinacionais produtoras e transformadoras (McCulloch \& Tweedale, 2008; David, 2008; Thébaud-Mony, 2014), eles escaparam até hoje a qualquer condenação penal, pelos crimes de trabalho de envenenamento de milhares e milhares de vítimas ${ }^{[7}\left[{ }^{8}\right]$.

Cem anos depois da criação da Organização Internacional do Trabalho cuja finalidade é agir em defesa dos direitos dos trabalhadores, será que a comunidade internacional pode deixar perdurar indefinidamente a impunidade dos agentes económicos responsáveis por catástrofes sanitárias como a do amianto, da qual os trabalhadores são as principais vítimas, mas também as mais invisíveis?

\section{BIBLIOGRAFIA}

David, M. (2008). Doubt is their product. How Industry's Assault on Science Treatens Your Health. New York: Oxford University Press.

Furuya, S., Chimed-Ochir, O., Ken Takahashii, K., David, A., \& Takala, J. (2018). Global Asbestos Disaster. International Journal of Environmental Research and Public Health, 15(5): 1000. https:// doi.org/10.3390/ijerph15051000

McCulloch, J., \& Tweedale, G. (2008). Defending the Indefensible. The Global Asbestos Industry and its Fight for Survival. New York: Oxford University Press.

Roudaire, J. (2018). Mémoires de luttes: quelques constats et réflexions. Communication au Colloque "Femmes - Cancer - Travail", Institut Syndical Européen (ETUI), Bruxelles, Belgique.

Thébaud-Mony, A. (2014). La science asservie. Santé publique: les collusions mortifères entre industriels et chercheurs. Paris: La Découverte. 


\section{NOTAS}

1. A tradução dos textos é feita sem acordo ortográfico. A edição online contém as adaptações ao novo acordo ortográfico.

2. http://www.ibasecretariat.org/press_release_feb_14_2020.pdf

3. http://ibasecretariat.org/press-release-stop-brazilian-asbestos-exports-apr-21-2019.pdf

4. http://www.ilo.org/public/english/standards/relm/ilc/ilc95/pdf/pr-20.pdf

5. Com efeito, a partir de 2006, no âmbito das sessões da Conferência das Partes desta Convenção, a grande maioria dos representantes e participantes têm vindo a defender a inscrição do amianto variedade crisotila no Anexo III para, como produto químico proibido ou severamente restringido, as suas exportações passarem a ser submetidas ao dito procedimento PIC. Note-se que nesse anexo já estão inscritas as variedades actinolite, antofilite, amosite, crocidolite e tremolite do amianto. Todavia, as expectativas, de que finalmente fosse decidido tal inscrição no Anexo III, esfumaram-se na reunião das Partes de junho de 2019, pois o consenso necessário, foi novamente impedido de se realizar por uma minoria de países produtores. E, mais uma vez, a questão da inscrição do amianto crisotilo, enquanto produto proibido, foi adiada e, agora, transferida para a agenda da próxima reunião da Conferência, prevista para o mês de julho de 2021 (http://www.pic.int/TheConvention/Overview/TextoftheConvention/tabid/1048/ language/en-US/Default.aspx).

6. https://www.who.int/occupational_health/publications/elim_asbestos_doc_fr.pdf?ua=1

7. https://blogs.mediapart.fr/annie-thebaud-mony/blog/211219/quand-lacondamnation-des-crimes-du-travail-pour-empoisonnement;

https://www.politis.fr/articles/2017/07/amiante-un-permis-de-tuer-pour-lesindustriels-37273/

8. Refira-se, de qualquer modo, os processos da justiça italiana contra Eternit e seu exadministrador e proprietário, Stephan Schmidheiny: https://www.asso-henri-pezerat.org/ stephan-schmidheiny-eternit-va-etre-juge-pour-homicide-volontaire/; https://charliehebdo.fr/ 2020/02/ecologie/fabrice-nicolino-suisse-amiante-industrie-proces-schmidheiny-philanthropecriminel/

\section{AUTORES}

\section{ANNIE THÉBAUD-MONY}

INSERM/IRIS, Université Sorbonne Paris Nord, 74 rue marcel Cachin, 93017 - Bobigny-Cedex annie.mony@gmail.com 